\title{
CLIMATE READY? EXPLORING THE IMPACTS AND LESSONS FROM RECENT EXTREME EVENTS AT ROYAL BOTANIC GARDEN EDINBURGH FOR CLIMATE CHANGE ADAPTATION IN THE HORTICULTURE SECTOR
}

\author{
Suzanne Martin ${ }^{l}$
}

\begin{abstract}
This article explores climate change and its current and potential impacts on botanic gardens. It highlights experiences of recent weather anomalies at the Royal Botanic Garden Edinburgh (RBGE) and its Regional Gardens and discusses how the learning gained from these anomalies is being used to increase the resilience of the Gardens to future climate change. This understanding is set in the context of a wider range of activities being pursued in relation to climate change adaptation in the horticulture sector, highlighting challenges and opportunities, and further sources of information which can be used by the managers of botanic gardens to inspire and inform climate change resilience planning.
\end{abstract}

\section{INTRODUCTION}

Weather and climate have implications for everyone, and horticulturists working in botanic gardens are likely to be particularly influenced by their impacts. In recent years there have been a series of well-publicised weather anomalies, including extreme weather events, experienced in Scotland and the rest of the UK. (For a summary of these see MET Office, 2012b.) Many climate scientists believe these events are indicative of the type of weather likely to be experienced more often in the future. In fact there is now an unprecedented consensus in the scientific community about the unequivocal evidence of global climate change (IPCC, 2007) and there is wide recognition that climate change is one of the most serious threats we face - at global, national and local scales. Climate change will have consequences for our society, economy and environment and will affect everyone in many different ways. It is critical that as well as reducing greenhouse gas emissions, referred to as 'climate change mitigation', we begin to better understand the impacts of climate change and adjust our activities so we are more resilient to cope with the risks and fulfil the opportunities which arise, referred to as "climate change adaptation'. In the long term, taking well-considered actions now will pay dividends in the future (Stern, 2007).

This article explores climate change and its current and potential impacts on botanic gardens. In particular it highlights experiences of recent weather anomalies at the Royal

1. Suzanne Martin is a Climate Change Policy Officer at RBGE. She works for the Scottish Government centre of expertise on climate change - ClimateXChange (www.climateXchange.org.uk).

Address: 20A Inverleith Row, Edinburgh, EH3 5LR, UK.

Email: S.Martin@rbge.org.uk 
Botanic Garden Edinburgh (RBGE) and its Regional Gardens at Dawyck (Peeblesshire), Benmore (Argyll) and Logan (Dumfries and Galloway). It discusses how the learning gained from these anomalies is being used to increase the resilience of the gardens to future climate change. The paper goes on to set this understanding in the perspective of a wider range of activities being pursued in relation to climate change adaptation in the horticulture sector, highlighting challenges and opportunities, and further sources of information which can be used by the managers of botanic gardens to inspire and inform climate change resilience planning. Indeed, whilst in the horticultural sector there has been a considerable focus on activities to reduce carbon emissions, there has been less shared consideration given to the ways in which the sector, and botanic gardens in particular, can adjust to better cope with the inevitable consequences of climate change (although some of the actions pursued will be beneficial to both).

\section{CLIMATE CHANGE IN SCOTLAND, THE UK AND GLOBALLY}

\section{Past climate trends and recent weather anomalies}

For several decades climate change has been hotly debated at global, national and local levels, with much speculation over issues such as its presence, extent and causes. Within the scientific community there is now an unprecedented agreement that climate change is occurring, with the Intergovernmental Panel on Climate Change (IPCC) concluding that "scientific evidence for warming of the climate system is unequivocal" (IPCC, 2007) and with 95 per cent certainty scientific evidence suggests humans are the dominant cause of global climate change since the 1950s (IPCC, 2013). These changes, caused by increasing greenhouse gas concentrations in the atmosphere, will affect both our weather and our climate. ${ }^{2}$ In fact, there is evidence that Scotland's climate is already changing. Between 1961 and 2004 the average temperature has risen by $1^{\circ} \mathrm{C}$, and during the same period, precipitation has increased by 21 per cent (SNIFFER, 2006). In particular there has been an increase in winter rainfall and in intense rainfall events (Adaptation Scotland, no date). Scotland has also experienced a 25 per cent reduction in snow cover, a decrease in the number of frost days (SNIFFER, 2006) and, if comparing 1961 to 2004, the growing season has lengthened by five weeks (SNIFFER, 2006).

As well as changes in the long-term average climate variables, Scotland (and the UK) has also experienced many weather anomalies (such as unseasonal weather and extreme weather events) in recent years. For example, in 2012 less than average quantities of rainfall from March to October brought drought to north-west Scotland (MET Office, 2013a). In contrast many other areas of Scotland, the south and east in particular (and England and Wales), were very wet during April and June 2012 (MET Office, 2013b). Many places had two to three times the monthly average rainfall, with

2. Weather is what we experience on a daily basis. Climate is a statistical characterisation of weather conditions averaged over a long period of time (often 30-year periods). 
April and June being the wettest in the UK since 1910 (MET Office, 2013b). Scotland and the UK have also experienced unusual extremes in temperature and storminess. In 2013, March and April were colder than average (in the UK it was the coldest March since 1962), with winds from the east or north bringing a significant wind chill (MET Office, 2013b). There was also widespread snow (MET Office, 2013b). The cold spring of 2013 contrasted starkly with the exceptionally warm temperatures in March 2012 which made it the third warmest March on record (BBC, 2012). In Scotland a new record for the highest March temperature was set three days in a row ${ }^{3}$ (BBC, 2012). Prior to this period, on 3 January 2012, the UK experienced its most severe wind storm for 13 years. The Central Belt of Scotland was especially badly affected with gusts of wind in excess of 130kph (MET Office, 2012b).

These experiences of climate and weather in Scotland (and the UK) reflect global changes. Global average temperatures have shown a warming trend over the last century and especially since the 1970s (Adaptation Scotland, no date). The year 2013 was among the top ten warmest years since records began in 1850, and 13 of the 14 warmest years on record have all occurred in the 21st century (World Meteorological Association, 2013). As the global mean temperature has increased, the occurrence of some extreme weather events has changed. The MET Office Hadley Centre (MET Office, 2012a) has found that in the last 50 years the number of cool days and nights has decreased and the occurrence of warm days and nights has increased. Indeed, for 2013 as a whole, most regions across the globe were warmer than average (NOA, 2013). Australia for example experienced its warmest year since records began in $1910\left(1.2^{\circ} \mathrm{C}\right.$ above average), Argentina had its second warmest year since records began in 1961 and Russia observed its sixth warmest year since 1891 (NOA, 2013).

Individual extreme weather events cannot be directly attributed to climate change as they occur, in part, because of the natural variability in our climate. ${ }^{4}$ Some of the weather anomalies experienced will therefore be counter to long-term climate change projections. Models however predict that climate change will result in an increased frequency and severity of some extreme events such as storms, floods and heatwaves. In a significant breakthrough, an international group of scientists including the MET Office Hadley Centre have been able to connect human-induced climate change to altered likelihoods of certain types of extreme events, for example an unusually warm November in the UK (such as the one in 2011) is 60 times more likely than during the 1960s (MET Office, 2012a). It can therefore be seen that we can no longer rely on past weather to guide our activities in the future; rather we need to consider the changing likelihood of occurrence of extreme events as well as other projected changes in climate (MET Office, 2012a). Possessed with knowledge of the likely direction and magnitude of trends we can start considering how best to plan for the future. To assist with this we can learn from periods

3. Aboyne in Aberdeenshire recorded $23.6^{\circ} \mathrm{C}$ on Tuesday 27 March, beating the record of $23.2^{\circ} \mathrm{C}$ set at Cromdale, near Grantown on Spey, the previous afternoon. The previous day Fyvie Castle in Aberdeenshire recorded $22.8^{\circ} \mathrm{C}$, beating a March temperature record which had stood for 55 years. See www.bbc.co.uk/news/uk-17595024

4. For information on future climate variability and predictability in Scotland, see http://bit.ly/PtsVMe 
when weather similar to that projected for the future is experienced. I now therefore turn to explore climate change projections for Scotland and the UK.

\section{Climate change projections for Scotland and the UK}

The UK is a world leader in meteorology and is fortunate to have some of the most robust and detailed climate change projections in the world. The UK Climate Projections (UKCP09) are based upon state-of-the-art climate modelling by the MET Office Hadley Centre UK Climate Impacts Programme (UKCIP) and over 30 contributing organisations. Climate projections for Scotland and the UK suggest summers will be drier and warmer, winters will be milder and wetter, and the weather will remain variable; it may become more variable, for example we may experience more heavy downpours of rain and more periods of drought, and we may also experience more stormy weather. There will be regional variations in climate change. For example, the west of Scotland is likely to see a greater mean increase in winter temperatures and precipitation than the north and east of Scotland. On the other hand, the west and east will see greater increases in mean summer temperatures and greater mean decreases in summer precipitation when compared to the north (Adaptation Scotland, no date).

Gardeners more than others are accustomed to making adjustments in their activities according to climatic variables such as temperature, rainfall and wind speed and direction; however, we are now experiencing, and in the future will be exposed to, climate change that is in many ways unprecedented (IPCC, 2013). If botanic gardens are to be resilient to climate change, there is a need for careful consideration of climate projections at national and regional scales, and their potential impacts (given local and site conditions). This knowledge in turn needs to be used to inform business continuity planning and adaptive actions so as to help botanic gardens reduce the long-term costs of climate change and make the most of the benefits it offers.

\section{ADAPTING TO CLIMATE CHANGE}

\section{Learning from weather anomalies}

There has been much written about the impacts of recent weather anomalies at RBGE and its Regional Gardens. Indeed, anomalies and extreme weather events are one of the most obvious ways we will feel tangible evidence of climate change. With climate change projections indicating that the variability in our weather will continue, and with even perhaps greater variability occurring, it becomes important to consider the learning which has occurred as a result of recent weather anomalies and to reflect upon how botanic gardens can use this understanding to become more resilient to climate change. This will now be explored in more detail in the context of the experiences of RBGE and its Regional Gardens. 


\section{Water availability}

As was noted earlier, climate change projections suggest we will experience drier (and warmer) summers, and wetter (and milder) winters, with rainfall more likely to occur via intense events. In keeping with the wetter than average weather across much of Scotland and the rest of the UK during the late spring and summer of 2012, overall 2012 was the wettest year on record at RBGE, with a total of $959.2 \mathrm{~mm}$ of rain (compared to annual average rainfall of 636mm since the 1950s) (David Knott, 2014 pers. comm.). In December 2013 and January 2014, the Garden experienced 259mm and 153mm more rain each month respectively than the 83-year average for that period (RBGE, 2014a). In 2012, Benmore saw the wettest June in ten years with 45 per cent above the average rainfall occurring. Indeed, the winter of 2013/14 was the UK's wettest winter since records began in 1910 (MET Office, 2014).

In 2012, the persistent heavy rain brought flooding and damage to beds, lawns and paths at RBGE (and its Regional Gardens). This hampered visitor access within the Garden because of the closure of waterlogged and slippery paths (Fig. 1). Waterlogging of the lawns also made grass cutting difficult and caused soil compaction. In some locations trees and shrubs had their roots submerged in water. To put right the damage, repairs were made to paths and beds where the soil and surface materials had been washed away (Fig. 2). A review of drainage was also carried out with existing drains

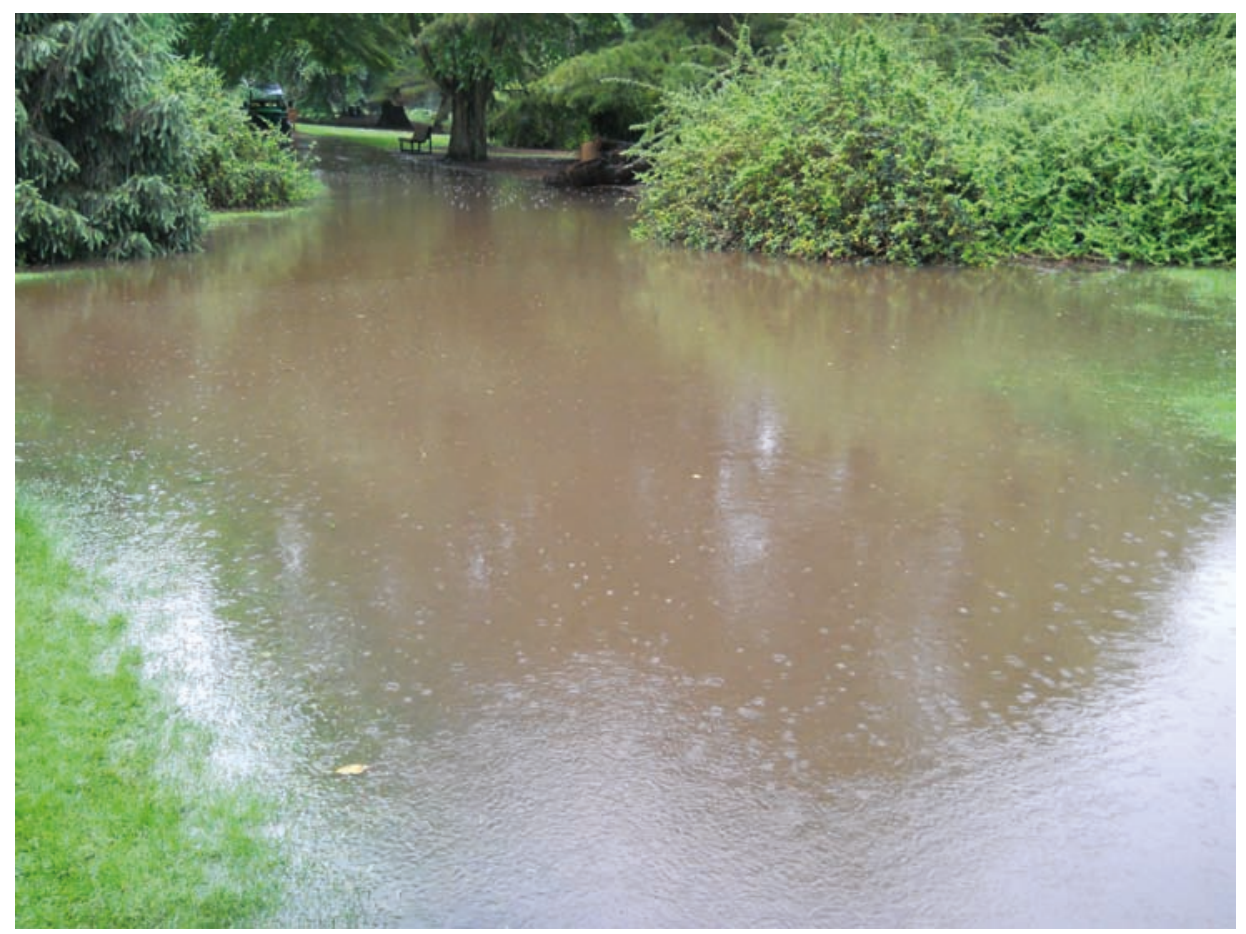

Fig. 1 Flooded path and lawn at RBGE, July 2012. Photo: David Knott. 


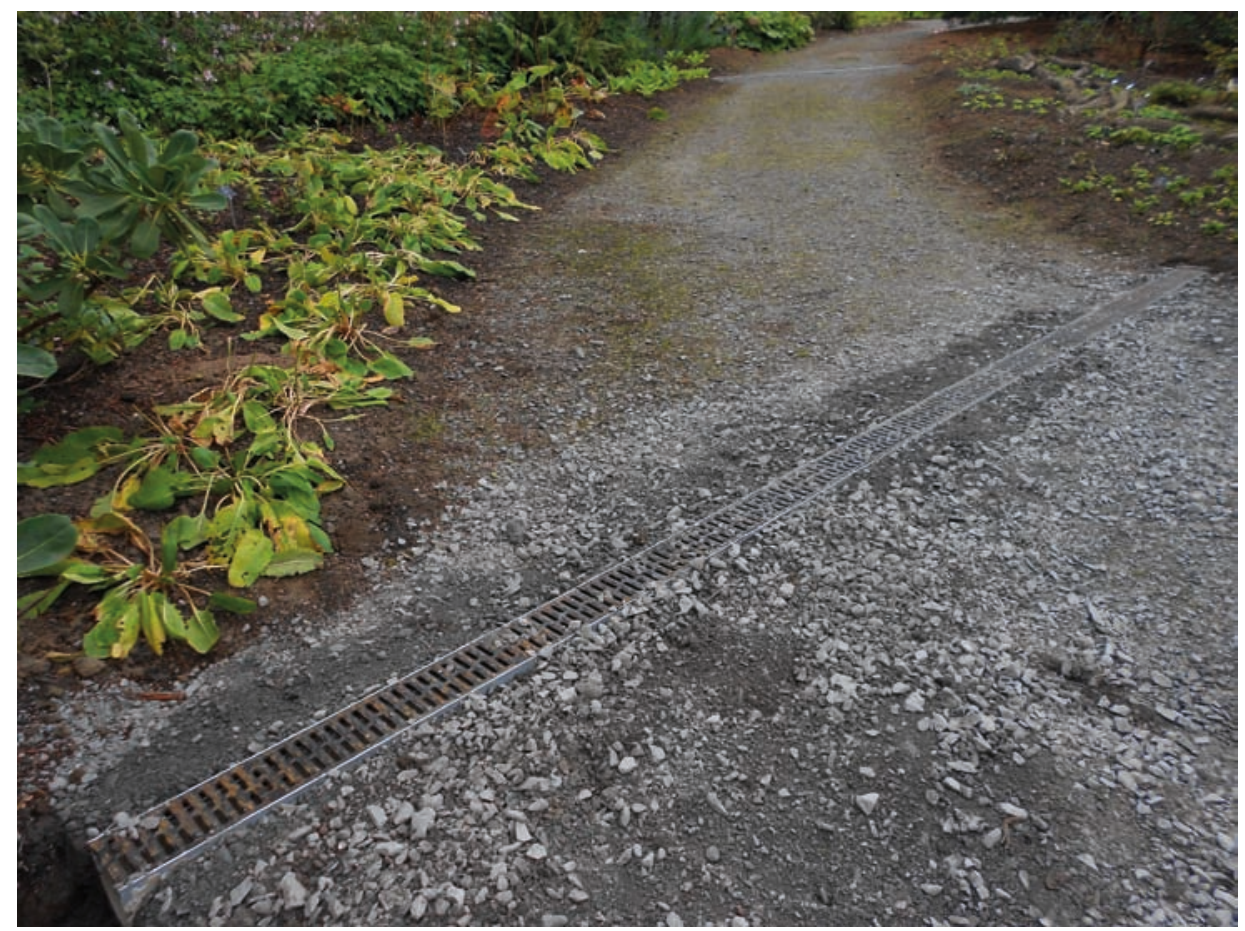

Fig. 2 Resurfaced path and new drainage at RBGE following erosion caused by flooding in July 2012. Photo: David Knott.

repaired where necessary and new drainage and soakaways installed in critical areas where capacity was not sufficient. This remains a rolling programme of work as different areas of the Garden are upgraded - indeed, it is important that climate proofing is built into all ongoing maintenance plans. RBGE also now uses rubber matting to prevent soil compaction of lawns in heavily used areas of the Garden.

Many of the impacts on the plants will become clearer over time, but one noticeable impact was a decrease in flowering of plants and an increase in vegetative growth. At Dawyck Botanic Garden, Curator Graham Stewart said of 2012, "This year we have been overwhelmed by the vegetative growth of many plants; in many cases it has been to the detriment of the flowers. Herbaceous perennials such as Rodgersia, Astilbe, Hosta and ferns needed constant pruning to keep them from overtaking our paths. Grass growth has also been phenomenal with the added problem that sometimes we couldn't cut it because the ground was saturated." (RBGE, 2013).

As well as periods of wetter than average weather, RBGE has also experienced drier than average periods. While drought stress has not been an issue to date, the dry period at the beginning of 2012 resulted in a need for irrigation in February (which is almost unprecedented); mulches have also been applied to help conserve soil moisture during dry spells. Extremes of wet and dry bring challenges in themselves, however climate 
change projections suggest we may experience more swings between increasingly wet and dry weather during the year. Botanic gardens will therefore need to be better able to cope with both an increasing frequency and severity of excessive rainfall and lack of water. For example, the extremely wet weather of late spring and early summer 2012 contrasted with a particularly dry spell in the east of Scotland (and eastern, central and southern England) during January and February 2012 when this area had less than 75 per cent of its normal rainfall. On the other hand, north-west Scotland received about 130 per cent of its normal rainfall during this period - which was then followed by drought (MET Office, no date).

Extremes in water availability, including a fluctuating water table, bring challenges for cultivation. Depending on the situation, it may demand the use of mulches to conserve soil moisture and the installation of irrigation and rainwater harvesting systems. There may also be a need for excessive vegetative growth to be pruned back, a change in the grass cutting regime and the use of matting or aeration techniques to reduce lawn compaction (Fig. 3). A regular regime of maintaining existing, and installing new, drains and soakaways and facilities for water collection (such as ponds) is also important, along with the replacement of concrete or tarmac paths with porous paving. All of these activities increase short-term garden maintenance costs but in the longer term will help to maintain the sustainability of botanic gardens and the important services they provide.

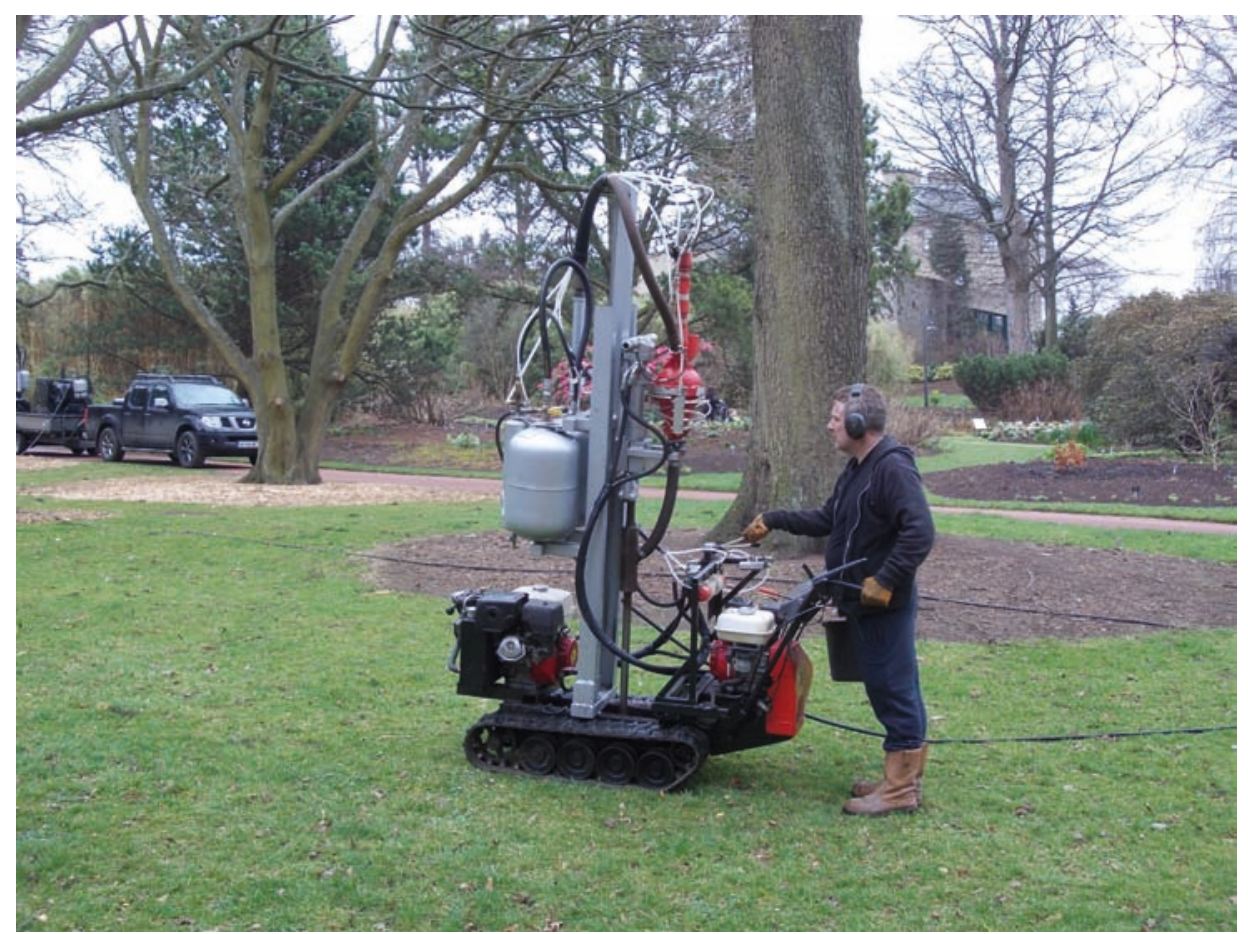

Fig. 3 Aeration of lawns at RBGE using a terralift. Photo: Martyn Dickson. 


\section{Temperature}

The UKCP09 projects that winters and summers will become warmer. Higher than average temperatures, particularly when prolonged and when combined with a lack of precipitation, may cause plants to suffer from heat stress. Whilst this has not yet been a problem at RBGE it has emphasised the need to ensure that plants are in the right Garden and in the right location in each Garden so as to reduce plant stress and therefore their vulnerability to climate changes and other factors such as pests and diseases. RBGE Collection Policy for the Living Collection (Rae et al., 2006) identifies climate change as an important consideration for the management of plants within the Gardens. As a result some plants have been relocated - for example, large-leaved Rhododendron (subsection Grandia) from Edinburgh (which is likely to have an increasingly drier summer climate) to Benmore which is wetter and has a climate more similar to that found in their native range. The location of plants in botanic gardens is an issue at a UK level, not just for RBGE. Therefore a coordinated approach, for example through organisations such as PlantNetwork (plantnetwork.org), at this scale would be beneficial.

In future it is expected that Scotland (and the rest of the UK) will have less severe winters. However, during the periods of December 2009 to January 2010 and November to December 2010, Scotland and the rest of the UK experienced two of the coldest winters in living memory. This had significant effects on RBGE - a loss of tender plants, freezing pipes, additional heating costs and an increased cost to keep the Garden open (for example as a result of the need to clear and grit paths). These impacts highlight the importance of having a contingency plan to deal with cold weather. Conversely a reduced frequency of very cold weather, including snow, may reduce our ability to cope with it when it does occur. As a result of experiences in winter 2009/10, RBGE is now better prepared to cope with severely cold and snowy weather by ensuring it has insulated water pipes and tanks and has sufficient snowploughs and other equipment required to clear paths.

Milder winters may result in fewer frost days in the future. At RBGE in 2013 and in the first two months of 2014 there were fewer frosts than usual. This has resulted in the grass lawns needing to be mown more frequently (and in every month of the year) and increased maintenance costs (David Knott, 2014 pers. comm.). Fluctuating temperatures such as those experienced in March 2012 when unseasonably warm weather was followed by a frost in early April may also bring difficulties, such as frost damage to tender shoots and leaves. Bisgrove (2008) however believes frost damage will generally be reduced but there may be a risk of increased frost damage in autumn when there is delayed dormancy in plants.

The impact of changing temperatures on plants in the Garden is, however, still unclear. Since $2002,{ }^{5} \mathrm{RBGE}$ has had a programme of research recording various aspects

5. Phenology research at RBGE dates back to 1850 when curator James McNab first recorded the flowering dates of over 40 species. The current programme of phenology research was established in 2002. The results of this project are well documented in many volumes of Sibbaldia. 
of plant phenology (recurring seasonal events), including, for example, the frequency and duration of flowering and changes in foliage for over a hundred species. This information is correlated with climate parameters such as temperature, rainfall and humidity. The project has found that during the last ten years early spring has been getting warmer and some spring-flowering plants have flowered more than two weeks earlier than normal. However, this is not without exception, as there have also been flowering events later than average years. RBGE is also a partner in the International Phenology Gardens Project which monitors the phenology of cloned material for a range of tree species. So as to provide data from a range of different local climates, project monitoring sites have been established at Dawyck, Logan and Benmore as well as at Edinburgh (RBGE, 2014). It is anticipated that both phenology projects will enable better predictions of how plants will respond to climate change and in turn that this will enable better climate change resilience planning in botanic gardens as well as more widely in the horticulture sector, and in forestry, agriculture and biodiversity management.

\section{Storminess}

There are many difficulties in identifying trends in wind speed - both in the past and into the future (Harding, 2012). Climate change projections suggest that in the future storms may be more frequent. Indeed, in recent years RBGE has experienced some exceptionally high winds, for example in January 2012, November/December 2013 and early January 2014. This has resulted in the Garden being shut on several occasions; for example in November 2013 it was closed for two full days and two half days (David Knott, 2014 pers. comm.). There have also been unseasonal high winds in the spring and summer.

On 3 January 2012, severe gale force to hurricane force winds caused unprecedented devastation to RBGE and the Regional Gardens. At Benmore, over 100 trees were lost, at Dawyck 15 trees collapsed and over 20 needed remedial work and at Logan there was extensive damage to trees and shrubs. At RBGE there was extensive damage to the plants within the Living Collection, particularly trees, and to the built infrastructure. In the Garden 34 trees were felled and a further 80 trees were damaged (Rae, 2012). Plants, particularly rhododendrons, were wind rocked (Rae, 2012) and suffered collateral damage from falling trees and branches. Others in previously shaded areas of the Garden were suddenly exposed to sunshine and drying winds (Beatty, 2012). Furthermore, over 600 panes of glass were shattered in the glasshouses, exposing many plants from the warmer climes of South East Asia to the cold (RBGE, 2012) (Fig. 4). Fortunately the loss of plants was limited as the damage occurred during a mild spell of weather and the concerted efforts ${ }^{6}$ of staff meant the glass was replaced within one week (RBGE, 2012).

6. Virtually all horticultural and maintenance staff came in to work, many interrupting their annual leave, and worked for six days until all the smashed panes of glass had been replaced (Beatty, 2012). 


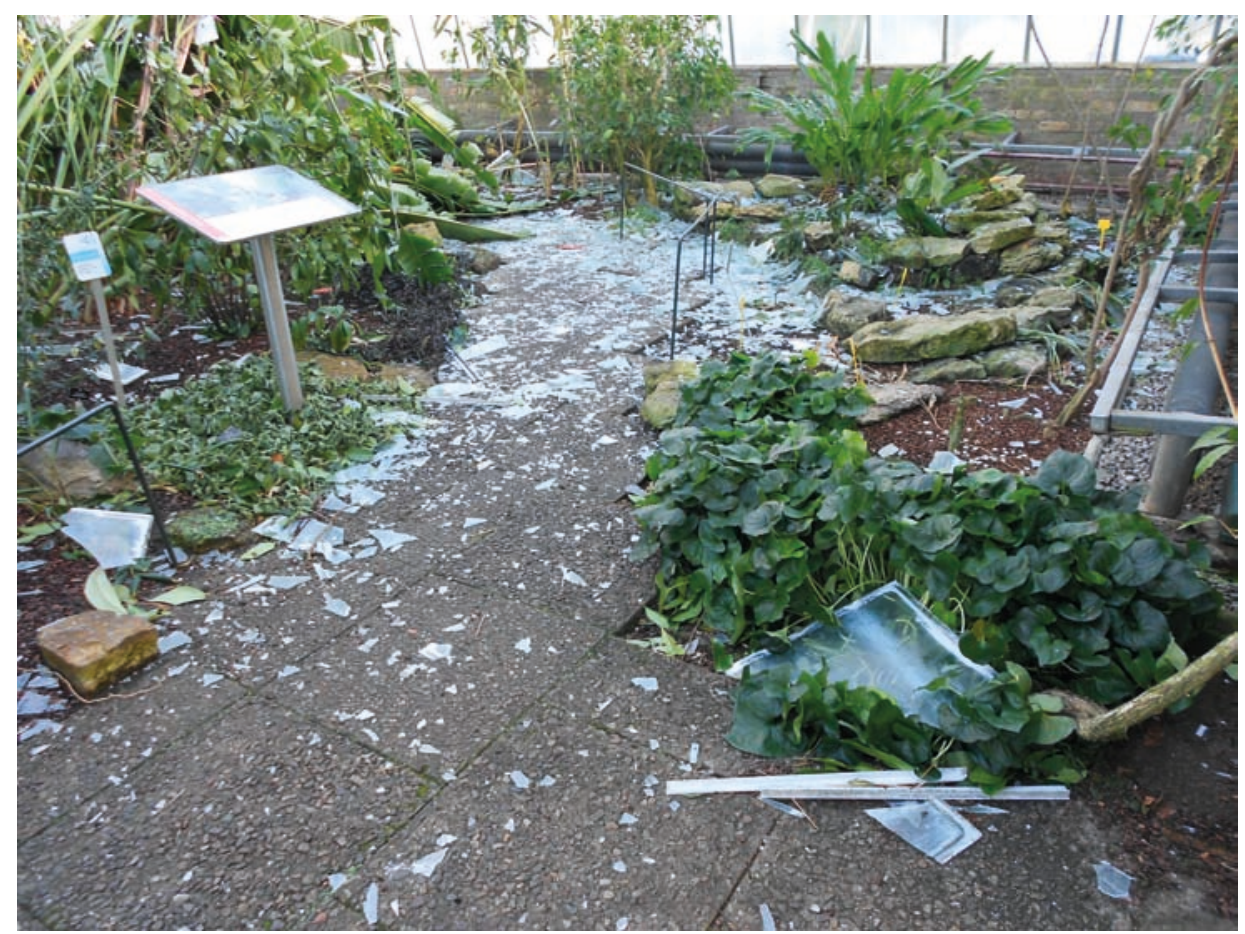

Fig. 4 Glass fragments in the Lowland Tropics glasshouse at RBGE caused by the storm on 3 January 2012. Photo: David Knott.

Had the wind coincided with a period of colder temperatures, the damage sustained to the plants could have been considerably greater (RBGE, 2012).

The immediate cost of tidying up after the storm was estimated to be at least $£ 100,000$ (Blackmore, 2012) but the longer-term costs were much greater. Indeed, so severe was the storm that 18 months later recovery work was still being undertaken, particularly at Dawyck and Benmore, where the terrain made the work particularly challenging (Knott, 2013). Across all of the Gardens, a range of specialist equipment and skills were required to put right the damage, along with a considerable sum of money. At Benmore alone additional chainsaws were purchased and foresters, stonemasons, a blacksmith and fencing contractor were employed, along with an excavator to clear tree roots (Beatty, 2012).

Whilst this was an extremely severe storm, in the future if stormy events become more commonplace (due to the warmer, moister atmosphere), organisations including botanic gardens will be expected and required to be more prepared and more able to cope with them. As a result of the storm in January 2012, RBGE has increased its storage of glass on site so that broken panes of glass can be more rapidly replaced. Funding of $£ 1.5$ million has also been secured from the Scottish Government as a contribution towards a $£ 40$ million redevelopment of the north-eastern corner of the Garden which 
contained many of the research glasshouses severely damaged in the storm. Whilst the redevelopment project had already been envisaged prior to the storm, the event emphasised and added urgency to the need to replace the ageing and 'off-the-shelf' research glasshouse structures to make them, amongst other features, more wind-resistant and energy-efficient. Whilst the architecturally designed Victorian and 1960s glasshouses were less damaged, the redevelopment project will also restore the stone and metal work of the Victorian Palm Houses and improve the energy efficiency of the glasshouses. Indeed climate change more generally opens up the opportunity for redesign of areas of the Garden. For example, there may be an opportunity to create new special collections of species, for example of plants threatened by climate change in other parts of the UK.

With high winds come health and safety risks to visitors and to staff. At RBGE trees are now more regularly assessed and maintained to reduce the risk of falling limbs and stems, and the glasshouses have also been assessed for wind stability. RBGE Garden Closure Policy for wind has been reviewed and the Garden is closed when the wind speeds reach $48 \mathrm{kph}$ or more, although due to the increased health and safety risk associated with their infrastructure, the Palm House and glasshouses are closed at a lower wind speed threshold. To inform staff decision making, RBGE has also installed an automatic anemometer at both the east and west sides of the Garden so that wind speeds can be monitored. The system operates so that once the wind speed reaches a threshold, an alarm sounds, signalling to staff there is a risk to personal health and safety and closure of the Garden should be considered.

\section{Pests, diseases and non-native invasive species}

In the last ten years there has been an increase in the number of new pests and diseases affecting plants in the UK and many of these have the potential to create severe difficulties for the cultivation of plants in botanic gardens. Climate change and the increasingly global nature of commercial horticulture are contributing factors to this increase. Conditions are less cold and more wet than before, particularly during winter, creating suitable conditions for fungal pathogens such as Phytophthora ramorum and $P$. lateralis. More generally, it is thought that milder and warmer weather will shorten the lifecycle of many pests and diseases (such as aphids and mites) and increase their survival during the winter; as such their population sizes may grow (Bisgrove and Hadley, 2002). Setting in place biosecurity measures that address risks when sourcing and raising plants, and to reduce spread of pests and diseases by staff and visitors, are vital, along with regular monitoring for signs of pests and diseases. Indeed, aside from inception at source, vigilance and early detection of pests and diseases is extremely important.

RBGE and its Regional Gardens have been forerunners in raising public awareness of pests and diseases and the need to consider biosecurity issues, for example installing disinfection mats at entrances to the Garden and placing visitor information about pests and diseases at various locations. At Edinburgh and Dawyck grass and bark paths have 
been replaced with gravel surfaces which prevent the collection of water, and therefore the potential for diseases such as Phytophthora ramorum to reproduce. Another prevention measure against $P$. ramorum has been a programme of removal for large areas of Rhododendron ponticum at Benmore ${ }^{7}$ (Knott, 2013).

\section{LOOKING TO THE FUTURE}

\section{Developing and sharing knowledge to build resilience}

The experience of RBGE and its Regional Gardens highlights the importance of anticipation and preparation. Horizon-scanning for trends, threats and opportunities, and then using the best available information to address risks and exploit opportunities in the short, medium and longer term is vital. To this end, climate change proofing should be built into routine maintenance and business planning. It is also important to ensure that contingency plans are in place to cope with unpreventable impacts arising from extreme events. Adaptation Scotland have recently produced a risk management plan template to assist in this process (Adaptation Scotland, no date). The same website contains a wealth of information and tools to help facilitate climate change adaptation planning.

At RBGE the staff have proved incredibly adept at coping with recent storms, floods and cold weather. Raising awareness amongst staff of issues around climate projections as well as extreme weather events is essential. It is also important to ensure that they have access to the best available information and, if necessary, training. It is also essential to exchange information and work in partnership with others addressing similar climate change issues. There are many examples in the horticultural sector of research and demonstration work taking place that will help managers to improve their understanding of how botanic gardens can cope better with current and projected changes in climate. In 2002, the University of Reading, funded by the Royal Horticultural Society (RHS), the National Trust and others, produced a report titled 'Gardening in the Global Greenhouse' (Bisgrove and Hadley, 2002). The report provided an identification of climate change projections for the UK and a comprehensive assessment of their likely impacts on gardens. It was updated in 2013, incorporating new climate change projections and information from a survey of public and horticultural organisations about their experience of climate change impacts. The report is due to be published in 2014 (Bernardini, 2013).

Other examples of work include trials at RHS Gardens. At Harlow Carr, North Yorkshire, heavy clay soil and a steadily increasing rainfall have exacerbated existing difficulties of waterlogging and flooding in the garden. Wetland planting has therefore been extended with a view to developing a better understanding about the cultivation of wetland plants that will be useful to gardeners as they face more wet weather in the future. Conversely, at Hyde Hall in East Anglia, which is situated in one of the driest

\footnotetext{
7. Rhododendron ponticum is a known host for Phytophthora ramorum.
} 
areas of the UK, the Dry Garden is being used to demonstrate how different plants can be cultivated without the need for artificial irrigation. Work has included improving the drainage in the heavy clay soil through the addition of sandy grit and the creation of raised mounds for planting. At Wisley water extraction has been reduced by 40 per cent and glasshouses and other structures have been designed to enable the collection of rainwater which is then stored in a lake for later use in the garden. Accompanying the trials there is a wide range of information on climate change on the RHS website (Royal Horticultural Society, 2013). Another interesting source of information and practical tips about climate change adaptation (and mitigation) is a long-running blog called 'My Climate Change Garden' (My Climate Change Garden, 2014).

While focused on urban parks rather than botanic gardens, Greenspace Scotland run a programme of work to promote and develop understanding of the role of green space in climate change adaptation (and mitigation). They have developed a toolkit and exemplary sites explaining and demonstrating how urban parks can be (re)designed to help them cope with climate change and make a contribution to climate change adaptation in the wider areas in which they are located (Greenspace Scotland, 2011). There are lessons to be drawn from this work for botanic gardens, particularly in urban areas, where green space can be used to contribute to wider climate change adaptation through, for example, the cooling of air temperatures and reduction of runoff and flooding. Indeed, within the horticultural sector itself the important current and future role of botanic gardens as exemplars in sustainable gardening is increasingly highlighted (see, for example, Bisgrove and Hadley, 2002). Some, such as Dr Casey Sclar, Executive Director of the American Public Gardens Association, argue that such gardens are "uniquely positioned to be the place to learn more about and experience climate change", in part due to their place as "natural bridges that link science and society" (Lewis, 2012).

Indeed, botanic gardens such as RBGE, as trusted centres of expertise in horticulture, visitor service provision and science, have huge potential to demonstrate and inspire the public about how they can manage their gardens at home so they can cope with climate change. Equally, they have a vital role in illustrating the value of gardens - both public and private - in helping our towns and cities to adapt to climate change, for example by cooling and cleaning the air, and reducing the amount of surface water runoff and flooding. At RBGE, the John Hope Gateway provides a venue for visitor learning - including a Real Life Science Studio, an education room and permanent and temporary exhibition space. It has hosted a number of events which focus on climate change issues, such as the recent 'Sea Change' event which brought together artists, scientists and environmentalists to explore the relationship between people, place and resources in the context of climate change. Within the Garden, interpretation boards provide information on climate change and weather issues in relation to plants and it is anticipated that refreshed interpretation and the Demonstration Garden when it is redesigned in 2015 will also include information on climate change. 


\section{SUMMARY}

Climate change is one of the most serious threats we face. In Scotland, the UK and globally, we are already experiencing the effects of climate change. It is not just an environmental issue, but cuts across all aspects of life and this is true for botanic and heritage gardens where it will have an impact on the natural and built infrastructure of gardens, horticultural and visitor operations, and on visitors and staff themselves.

Early and coordinated adaptation to help minimise the impacts and sustain the delivery of important horticultural and visitor services across botanic gardens is vital. It is particularly important that managers of botanic gardens understand the current and potential impacts of a changing climate, and then make use of the best available information to address them through routine maintenance including business continuity planning. Business continuity planning should address opportunities as well as threats, for example the potential to evolve the role of botanic gardens as centres of excellence for the communication of climate change adaptation (and wider sustainable) gardening practices, or the role of green space in helping society to become more resilient to the climate. It is also important to ensure contingency plans are in place to cope with unpreventable impacts, for example arising from extreme events, and that funds are available to remediate any damage caused to the plants and built infrastructure.

The knowledge and skills of staff are critical to the ability of organisations, including botanic gardens, to cope with climate change. As such, awareness raising and training of employees is an essential climate change adaptation action, along with the development of a stronger exchange of information and partnership amongst the horticultural sector and others addressing similar climate change issues. Indeed, there is much that botanic gardens can do to better prepare themselves and others to be resilient under a changing climate. If they are to fulfil their potential to be exemplars of sustainable gardening, it is critical that as they adapt, they share their learning and inspire others, both within and outside the horticultural sector, to also embark on the journey of climate change adaptation.

\section{ACKNOWLEDGEMENTS}

With thanks to David Knott and Chris Ellis for the information and comment they provided in support of this paper.

\section{REFERENCES}

ADAPTATION SCOTLAND (no date). Adapting to Climate Change: an introduction for public sector policy makers, resource managers and practitioners. Available at: www. adaptationscotland.org.uk (Accessed: 1 February 2014).

BBC (2012). 'March weather third warmest on record - says MET Office'. Available at: www. bbc.co.uk/news/uk-17595024 (Accessed: 3 March 2014). 
BEATTY, R. (2012). Repair and renewal, The Botanics 49: 4-6. Available at: http://www.rbge. org.uk/about-us/publications/the-botanics/the-botanics-back-issues (Accessed: 5 March 2014).

BERNARDINI, C. (2013). Gardening in a Changing Climate. Available at: http://blogs.reading. ac.uk/crg/climate-change-and-gardening (Accessed: 2 April 2014).

BISGROVE, R. \& HADLEY, P. (2002). Gardening in the Global Greenhouse - the impacts of climate change on gardens in the UK. Technical Report. November 2002. University of Reading.

BLACKMORE, S. (2012). Foreword, The Botanics 48: 2. Available at http://www.rbge.org.uk/ about-us/publications/the-botanics/the-botanics-back-issues (Accessed: 4 March 2014).

GREENSPACE SCOTLAND (2011). Greenspace and climate change. Available at: www. greenspacescotland.org.uk/greenspace-and-climate-change.aspx (Accessed: 4 March 2014).

HARDING, A. (2012). Current and future wind storms in Scotland. ClimateXChange briefing note. Available at: http://bit.ly/PtsVMe (Accessed: 3 March 2014).

IPCC (2007). Fourth assessment report: climate change 2007 (AR4). Available at: www.ipcc.ch/ publications_and_data/publications_and_data_reports.shtml (Accessed: 3 February 2014).

IPCC (2013). Fifth assessment report: climate change 2013 (AR5). Available at: www.ipcc.ch/ publications_and_data/publications_and_data_reports.shtml (Accessed: 3 February 2014).

KNOTT, D. (2013). Developments - recent and planned activities at Benmore, Dawyck and Logan, RBGE Annual Report 2012/13 24-25. Available at: www.rbge.org.uk/assets/files/ about_us/Corporate_Info/annualreport1213lores.pdf (Accessed: 6 March 2014).

LEWIS, C. (2012). Climate change and public gardens - an interview with Dr Casey Sclar, Public Garden. Journal of the American Public Gardens Association 27: 5-6.

MET OFFICE (no date). Winter 2011/12. Available at: www.metoffice.gov.uk/climate/uk/2012/ winter.html (Accessed: 2 March 2014).

MET OFFICE (2012a). Our changing climate: trends, extremes, attribution and projections. Available at: http://www.metoffice.gov.uk/media/pdf/0/8/part_1_Our_Changing_Climate.pdf (Accessed: 12 February 2014).

MET OFFICE (2012b). Winter storms early January 2012. Available at: www.metoffice.gov.uk/ climate/uk/interesting/2012_janwind (Accessed: 12 February 2014).

MET OFFICE (2013a). England and Wales drought 2010 to 2012. Available at: www.metoffice. gov.uk/climate/uk/interesting/2012-drought (Accessed: 12 February 2014).

MET OFFICE (2013b). Record rainfall April to July 2012. Available at: www.metoffice.gov.uk/ climate/uk/interesting/april-july2012 (Accessed: 12 February 2014).

MET OFFICE (2013c). Snow and low temperatures late March 2013. Available at: www. metoffice.gov.uk/climate/uk/interesting/march2013-snow (Accessed: 12 February 2014).

MET OFFICE (2014). Winter so far - 20th February rainfall update. Available at: http:// metofficenews.wordpress.com/2014/02/20/winter-so-far-20th-february-rainfall-update/ (Accessed: 20 February 2014).

MY CLIMATE CHANGE GARDEN (2014). Available at: www.myclimatechangegarden.com/ blog (Accessed: 2 March 2014). 
NOAA (2013). Global analysis - annual 2013. Available at: www.ncdc.noaa.gov/sotc/ global/2013/13 (Accessed: 16 February 2014).

RAE, D. (2012). Storm damage and restoration, RBGE Annual Report 2011/12 23. Available at: http://www.rbge.org.uk/assets/files/Publications/annualreport1112lores.pdf (Accessed: 2 March 2014).

RBGE (2012). Extraordinary weather and its effect on RBGE Botanic Gardens' trees and plants. Press release. RBGE, Edinburgh.

RBGE (2014a). Benmore weather extracts - precipitation and temperature, December 2013February 2014. Unpublished.

RBGE (2014b). Phenology projects. Available at: www.rbge.org.uk/science/plants-and-climatechange/phenology-projects (Accessed: 2 March 2014).

ROYAL HORTICULTURAL SOCIETY (2013). Gardening in a changing climate. Available at: www.rhs.org.uk/climate (Accessed: 2 March 2014).

SNIFFER (2006). An online handbook of climate trends across Scotland. Available at: www. climatetrendshandbook.adaptationscotland.org.uk/index.html (Accessed: 3 March 2014).

STERN, N. (2007). The Economics of Climate Change: The Stern Review. Cambridge University Press, Cambridge.

WORLD METEOROLOGICAL ASSOCIATION (2013). WMO: 2013 among top ten warmest on record. Press Release No. 983. Available at: www.wmo.int/pages/mediacentre/press releases (Accessed: 18 February 2014).

\section{FURTHER SOURCES OF INFORMATION}

Adaptation Scotland. Available at: www.adaptationscotland.org.uk

UKCP09. Available at: http://ukclimateprojections.metoffice.gov.uk/21678

Summary of climate change projections for Scotland. Available at: www.scotland.gov.uk/ Publications/2009/12/08130513/3 